LIFE IN THE COSMOS 



\section{LIFE IN THE COSMOS}

From Biosignatures to Technosignatures

Manasvi Lingam | Avi Loeb

Harvard University Press

Cambridge, Massachusetts | London, England 2021 
Copyright (C) 2021 by the President and Fellows of Harvard College All rights reserved

Printed in the United States of America

First printing

Cover design by Jill Breitbarth

Cover photo: sdecoret / Shutterstock

9780674259942 (EPUB)

9780674259959 (PDF)

The Library of Congress has Cataloged the Printed Edition as Follows:

Names: Lingam, Manasvi, 1987- author. | Loeb, Avi, author.

Title: Life in the cosmos : from biosignatures to technosignatures /

Manasvi Lingam and Avi Loeb.

Description: Cambridge, Massachusetts : Harvard University Press, 2021. I

Includes bibliographical references and index.

Identifiers: LCCN 2020048895 | ISBN 9780674987579 (cloth)

Subjects: LCSH: Exobiology. | Life on other planets. |

Life-Origin. | Habitable planets.

Classification: LCC QH326 .L564 2021 | DDC 576.8/39—dc23

LC record available at https://lccn.loc.gov/2020048895 
To our cherished families, friends, and the myriad denizens weaving their lives amidst the Sternenzelt of the Cosmos 
